\title{
On the Optimality of Bank Runs: Comment on Allen and Gale
}

MARGARITA SAMARTÍN

samartin@emp uc3m es

Universidad Carlos III de Madrid, Departamento de Economía de la Empresa, Calle Madrid 126,

28903 Getafe, Spain

\section{Abstract}

This paper presents a model consistent with the business cycle view of the origins of banking panics As in Allen and Gale (1998), bank runs arise endogenously as a consequence of the standard deposit contract in a world with aggregate uncertainty about asset returns The purpose of the paper is to show that Allen and Gale's result about the optimality of bank runs depends on individuals's preferences In a more general framework, considered in the present work, a laissez-faire policy can never be optimal, and therefore, regulation is always needed in order to achieve the first best This result supports the traditional view that bank runs are costly and should be prevented with regulation

Key words: bank regulation, bank runs, deposit contracts, optimal risk sharing, suspension of convertibility

JEL Classification No.: G21, G28, D8

\section{Introduction}

The banking system has traditionally been vulnerable to the problem of bank runs, in which many or all depositors at a bank attempt to withdraw their funds simultaneously. If these withdrawals at a particular bank then spread across banks in the same region or country they may generate a banking panic. These financial crises are costly and are prevented with different intervention measures.

Banking panics were common in the US and Europe prior to the 20th century. Suspension of convertibility or central bank intervention were the usual tools to deal with panics. However, most of the regulatory systems that prevailed in the US and Europe until the 1980s, evolved as a consequence of the financial crisis of the 1930s. ${ }^{1}$ The Great Depression (1929-1933) had an important impact on the financial system of the US ${ }^{2}$ and led to the creation of the Federal Deposit Insurance Corporation. This institution insured deposits up to $\$ 2500$. Deposit insurance ${ }^{3}$ was an excellent measure to eliminate runs and there was a calmer period after World War II. However, the market induced desintermediation of the 1970s, in the face of inflation and nominal rigid interest rate ceilings, and the Banking Directives in Europe generated a deregulation of the banking systems in the US and Europe in the 1980s. The experience with bank deregulation has not been entirely pleasant. Many US Savings and Loans failed in the 1980s and some European countries have also experienced 
problems in the 1990s. Furthermore, many emerging countries have had severe problems in their banking systems in recent years. All this has led to a rethinking of the framework of banking regulation.

Theoretical research on banking theory has focused on analyzing the microeconomic role of banks in the economy (e.g. Bryant [1980], Diamond and Dybvig [1983], Bhattacharya and Gale [1987], Jacklin and Bhattacharya [1988], Chari and Jagannathan [1988], and Allen and Gale [1998]). This stream of research has approached banking panics through two different types of models.

First, the models of pure panic runs comprise those models in which bank runs occur as random phenomena, with no correlation with other economic variables. Bryant [1980], followed by Diamond and Dybvig [1983], made a significant contribution by modeling the demand for liquidity and the transformation service provided by banks. They demonstrated that demand deposit contracts, which enable the transformation of illiquid assets into more liquid liabilities, provide a rationale both for the existence of banks and for their vulnerability to runs. The optimal contract yields a higher level of consumption for those who withdraw early than the technological return. Bank runs, thus, take place when the idea of deposit withdrawals spills over economic agents (an essential point is that banks satisfy a sequential service constraint, see Wallace [1988]). The model concludes that with no aggregate uncertainty, a suspension of convertibility policy eliminates the bank run equilibrium. Otherwise, a deposit insurance policy would be more effective. Diamond and Dybvig's model attracted severe criticisms (e.g., Gorton [1988]) for assuming that bank runs are random phenomena, and thus, uncorrelated with other economic variables. Gorton [1988], in an empirical study of bank runs in the US during the National Banking Era (1863-1913), found support for the notion that bank runs tended to occur after business cycle peaks.

Second, models of information-induced runs assert that bank runs occur due to the diffusion of negative information among depositors about a bank's solvency, and therefore are not the result of sunspots. These type of models is consistent with the business cycle view of the origin of panics (e.g., Jacklin and Bhattacharya [1988], Chari and Jagannathan [1988], and Allen and Gale [1998] among others). Jacklin and Bhattacharya [1988] examined the relative degrees of risk-sharing provided by bank deposit and traded equity contracts. They focused on the relationship between the riskness of and information on the stream of returns, and the desirability of equity versus deposit contracts. They found that deposit contracts tended to the better for financing low risk assets. Chari and Jagannathan [1988] drew on both information-induced and pure panic runs models ${ }^{4}$ to study the effects of extra market constraints, such as suspension of convertibility on bank runs. They concluded that such constraints prevent bank runs and result in superior allocations. Despite the importance of this contribution, it raised considerable criticisms due to: (i) the ambiguous role of banks or any other financial intermediary in the model, (ii) assuming that individuals were risk neutral. An interesting addition to this literature is the recent paper by Allen and Gale [1998]. In constrast to previous literature, ${ }^{5}$ which has focused mainly on modeling bank runs, this paper analyzes the optimal intervention policy that should be implemented, if any, to deal with panics. As in Diamond and Dybvig, individuals have corner preferences, that is, at date 1 , agents have realized utility for date 1 or date 2 consumption only. However, in this model the bank invests in a risky technology and individuals receive information about returns at 
date 1. Bad information has then the power to precipitate a crisis. The paper shows that under certain circumstances, bank runs can achieve the first best outcome, as they allow efficient risk sharing among depositors and they allow banks to hold efficient portfolios. This result seems to contradict the traditional history of regulation, based on the premise that banking panics are bad and should be eliminated. However, if there are liquidation costs or markets for risky assets are introduced, laissez-faire is no longer optimal, and central bank intervention is needed to achieve the first best.

In the present paper it will be shown that even if there are no liquidation costs, a laissezfaire policy is not optimal, provided individuals' preferences are smooth. The model presented here is consistent with the business cycle view of the origins of banking panics. As in Allen and Gale [1998], banks operate in a competitive environment and so they offer deposit contracts that maximize the expected utility of the consumers. The behavior of the banking industry is thus represented by an optimal risk sharing problem. The paper considers two different risk sharing problems: it is first assumed that banks can write contracts where the amounts individuals withdraw at each date can be made contingent on the return on the risky asset. This problem provides a benchmark for optimal risk sharing. Secondly, and in line with Allen and Gale's paper, we consider a standard contract, which offers individuals fixed payments at each date, and which is therefore by definition "non contingent". In this second case, bank runs arise endogenously as a result of the negative signal which is observed by some depositors in the interim period. However, the key difference with Allen and Gale [1998] is that in this paper individuals' preferences are describable as s ooth, that is, at date 1 agents derive utility for consumption in both periods of their lives (although type-1 agents derive relatively more utility for consumption in period 1 than type- 2 agents). ${ }^{6}$ This framework allows for total bank runs, as opposed to Allen and Gale [1998] where runs were always partial. In their case, as type-1 agents derive only utility for consumption at date 1, being the only type- 2 to stay the course would give the investor infinite returns when the long-term asset return is close to zero. By contrast, in this model, as both types of agents consume in the two periods, the lone type- 2 simply obtains a somewhat larger share of a very small pie. Type- 2 agents are then better off by running on the bank. However, if all type- 2 agents run, they would consume too much at date 1 relatively to the first best. The bank can then restrict payments at date 1 if the bank's return is very low, and this will reduce the amount of first period cash that type- 2 individuals obtain by imitating type- $1 \mathrm{~s}$ to the point to which they are willing to follow the type- 2 plan.

The contribution of the present paper is in this sense to show that Allen and Gale's result about the optimality of bank runs depends on individuals' preferences. In a more general framework, considered in the present work, standard contracts and bank runs can never achieve the first best outcome, unless payments are restricted at date 1. This result supports the traditional view that bank runs are costly and should be prevented with regulation.

The structure of the paper is as follows: The basic framework of the model is presented in Section 2. As mentioned above the behavior of the banking industry is characterized by the optimal, incentive compatible risk sharing problem. Two different risk sharing problems are considered. In Subsection 2.1 we assume that the optimal allocation can be made contingent on the return on the risky asset, and is considered as the benchmark case. In Subsection 2.2 we consider the case in which banks offer standard contracts, that are not contingent on 
the return on the risky asset. However, individuals can observe this return and make their withdrawal decision conditional on it. It is shown that when individuals' preferences are smooth, standard contracts and bank runs can never achieve optimal risk sharing unless a suspension of payments policy is implemented. Finally, Section 3 concludes the paper.

\section{The model}

There is an economy going through a sequence of three periods $(T=0,1,2)$ and one good per period. There are two types of assets: a safe asset and a risky one. The safe asset transforms one unit of the consumption good at $T$ into one unit of the consumption good at $T+1$. It can be thought of as a storage technology. The risky asset transforms one unit of the consumption good at $T=0$ into $\tilde{R}$ units of the consumption good at $T=2$, and where $\tilde{R}$ is a nonnegative random variable with a probability density function $f(R)$. For simplicity, it is assumed that the long-term technology cannot be liquidated early, or equivalently, no costs for early withdrawals are assumed.

On the household side of the economy there is a continuum of ex-ante identical agents, who are endowed with $k_{0}$ units of the good at $T=0$ and that maximize expected utility of consumption. They are subject at $T=1$ to a privately observed uninsurable risk of being of either of two types. They can be of type- 1 with probability $t_{1}$ or of type- 2 with probability $t_{2}$. The difference between types is that type-1 agents derive relatively more utility from consumption in the first period with respect to type- 2 agents. The following form for the utility function is assumed:

$$
U^{j}\left(c_{1 j}, c_{2 j}, \rho_{j}\right)=\rho_{j} \ln c_{1 j}+\left(1-\rho_{j}\right) \ln c_{2 j}
$$

where $j=$ type $=1,2$. For simplicity, the following values for the parameter $\rho_{j}$ will be considered: $\rho_{1}=\rho>0.5, \rho_{2}=1-\rho<0.5$ and $0 \leq \rho_{2} \leq \rho_{1} \leq 1$. Note that Allen and Gale's results can simply be derived as extreme cases corresponding to $\rho_{1}=1$ and $\rho_{2}=0$.

At $T=1$ depositors observe a signal, which predicts with perfect accuracy the value of $R$ that will be realized at date 2 .

It is finally assumed no aggregate uncertainty so that with probability 1 a fraction $t_{1}$ of consumers are of type- 1 and a fraction $t_{2}$ of type- 2 and also the expected return is greater than one $(E[R]>1)$, that is, the risky asset is more productive than the safe one.

The following notation will be used throughout the paper:

$$
\mu=\frac{1-\rho}{\rho}, \quad t_{1 m}=\frac{t_{1}+t_{2} \mu}{1+\mu}, \quad t_{2 m}=\frac{t_{2}+t_{1} \mu}{1+\mu}
$$

and where $0<\mu<1$ and $t_{1 m}+t_{2 m}=t_{1}+t_{2}=1$.

\subsection{The optimal incentive-compatible risk sharing problem}

As a benchmark case, it is first assumed that banks can write contracts where the amount that is withdrawn at each date can be made contingent on the random return $(\tilde{R})$. The deposit contract can be represented by the functions $c_{1 j}(R), c_{2 j}(R)(i=1,2)$, which specify consumption at dates 1 and 2 for a type $j$ consumer. 
The optimal risk sharing problem can be written as follows:

$$
\begin{array}{ll}
\max _{c_{i j}, k_{1}, k_{2}} & \left\{E_{\tilde{R}}\left[t_{1} U^{1}\left(c_{11}(R), c_{21}(R), \rho_{1}\right)+t_{2} U^{2}\left(c_{12}(R), c_{22}(R), \rho_{2}\right)\right]\right\} \\
\text { s.t. } \quad k_{1}+k_{2} \leq k_{0} & \\
& t_{1} c_{11}(R)+t_{2} c_{12}(R) \leq k_{1} \\
& t_{1}\left[c_{21}(R)+c_{11}(R)\right]+t_{2}\left[c_{22}(R)+c_{12}(R)\right] \leq k_{1}+k_{2} R \\
U^{j}\left(c_{1 j}(R), c_{2 j}(R), \rho_{j}\right) \geq\left[U^{j}\left(\delta_{j} c_{1 i}(R),\left(1-\delta_{j}\right) c_{1 i}(R)+c_{2 i}(R), \rho_{j}\right)\right] \\
\text { for } i \neq j ; \quad i, j=1,2 ; \quad 0 \leq \delta_{j} \leq 1
\end{array}
$$

where $c_{1 j}(R)$ represents consumption at time $T=1$ for a type $j$ agent, $c_{2 j}(R)$ consumption at time $T=2$ for a type $j$ agent, $k_{1}$ is the investment in the safe asset at $T=0$ and $k_{2}$ is the investment in the risky asset at $T=0$. The first constraint states that the total amount invested must be less or equal to the amount deposited. The second constraint says that the investment in the safe asset should be enough to cover consumption at date 1 . The third one represents the fact that the investment in the risky asset plus the amount of the safe one that is left over from period one should be enough to cover consumption at date 2 , that is: ${ }^{7}$

$$
t_{1} c_{21}(R)+t_{2} c_{22}(R) \leq k_{2} R+\left[k_{1}-t_{1} c_{11}(R)-t_{2} c_{12}(R)\right]
$$

The last two constraints are incentive compatibility constraints. In the case of a type2 agent, incentive compatibility requires that the utility obtained from the consumption bundle the individual receives if he is honest $\left(c_{12}(R), c_{22}(R)\right)$, should be at least as large as the utility obtained by lying and behaving like a type-1 agent, that is, obtaining the consumption bundle $\left(c_{11}(R), c_{21}(R)\right)$ and then reinvesting his first period consumption in the storage technology in the optimal way for him. This means consuming $\delta_{2} c_{11}(R)$ in the first period and $\left(1-\delta_{2}\right) c_{11}(R)+c_{21}(R)$ in the second period. The same for type- 1 agents. ${ }^{8}$

However, in solving the optimal risk sharing problem, the incentive compatibility constraints can be dispensed with. ${ }^{9}$ The problem is solved subject to the three constraints and it can be shown that the incentive constraints are always satisfied. The following result is obtained:

Theorem 1: The solution $\left[k_{1}, k_{2}, c_{i j}(R)\right]$, to the optimal risk sharing problem is characterized by the following conditions:

$$
\begin{aligned}
& \text { if } r \leq 1 \text { (case 1) } \\
& c_{11}(R)=c_{22}(R)=\frac{1}{1+\mu} \frac{k_{1}}{t_{1 m}}\left[t_{1 m}+r t_{2 m}\right] \\
& c_{21}(R)=c_{12}(R)=\mu c_{11}(R) \\
& \text { if } r>1 \text { (case 2) } \\
& \quad c_{11}(R)=\frac{1}{1+\mu} \frac{k_{1}}{t_{1 m}} \quad c_{12}(R)=\mu c_{11}(R) \\
& c_{22}(R)=r c_{11}(R) \quad c_{21}(R)=\mu c_{22}(R)
\end{aligned}
$$


and $k_{1}, k_{2}$, the values that maximize the following expression:

$$
\begin{aligned}
& \max _{k_{1}, k_{2}}\left[\int_{0}^{1} U^{*(1)} f(r) d r \frac{t_{2 m}}{t_{1 m}} \frac{k_{1}}{k_{2}}+\int_{1}^{\infty} U^{*(2)} f(r) d r \frac{t_{2 m}}{t_{1 m}} \frac{k_{1}}{k_{2}}\right] \\
& \text { s.t. } \quad k_{1}+k_{2}=k_{0}
\end{aligned}
$$

where $U^{*(1)}$ and $U^{*(2)}$ are the utility functions corresponding to the cases $r \leq 1$ and $r>1$ respectively, and where the random variable $r$ (from now on, the specific return) is defined as follow:

$$
r=R \frac{\left(k_{2} / k_{1}\right)}{\left(t_{2 m} / t_{1 m}\right)}
$$

Proof. See Appendix B for a detailed resolution of the problem.

An example of the optimal contract is illustrated in figure $1 .{ }^{10}$ As long as $r \leq 1$, the optimal allocation implies storing part of of the liquid asset to date 2 in order to compensate the low returns on the risky asset in this period. When the signal indicates that $R$ will be high at date 2 (i.e $r>1$ ), then the liquid asset is completely exhausted for date 1 consumption, since consumption at date 2 will be high in any case. In case 1 , first and second period consumption depend on $R$. In case 2, first period consumption is constant and second period consumption depends on $R$. For the parameter values of the example, the optimal levels of the initial investments are $k_{1}^{*}=0.52$ and $k_{2}^{*}=0.48$ and the expected utility achieved is -0.3757 .

\subsection{Optimal risk-sharing through deposit contracts with bank runs}

Following Allen and Gale [1998], we now consider the situation in which banks are restricted to use standard contracts, as observed in practice.

In particular, let a demand deposit contract be defined as a contract that requires an initial investment at $T=0$ with the intermediary in exchange for the right to withdraw per unit of initial investment (at the discretion of depositor and conditional on the bank's solvency) either $\bar{c}_{11}$ units in period 1 and $c_{21}(R)$ units in period 2 or $\bar{c}_{12}$ units in period 1 and $c_{22}(R)$ units in period 2. As shown by Jacklin [1987], the demand deposit contract optimally combines the two types of deposits that banks usually hold, a time deposit and a more typical demand deposit contract. ${ }^{11}$ The standard demand deposit contract is by definition "non-contingent". The reason the contractual deposit payoffs in the interim period can not depend on $R$ is because information about this future random return is not verifiable (even though some have it). It is based on an assumption of private information about the bank's asset returns, which makes for the inflexibility in the deposit contract terms. ${ }^{12}$ In this sense the only risk the depositors bear is that they will not be repaid their money in the situation in which it is physically impossible to repay them. 


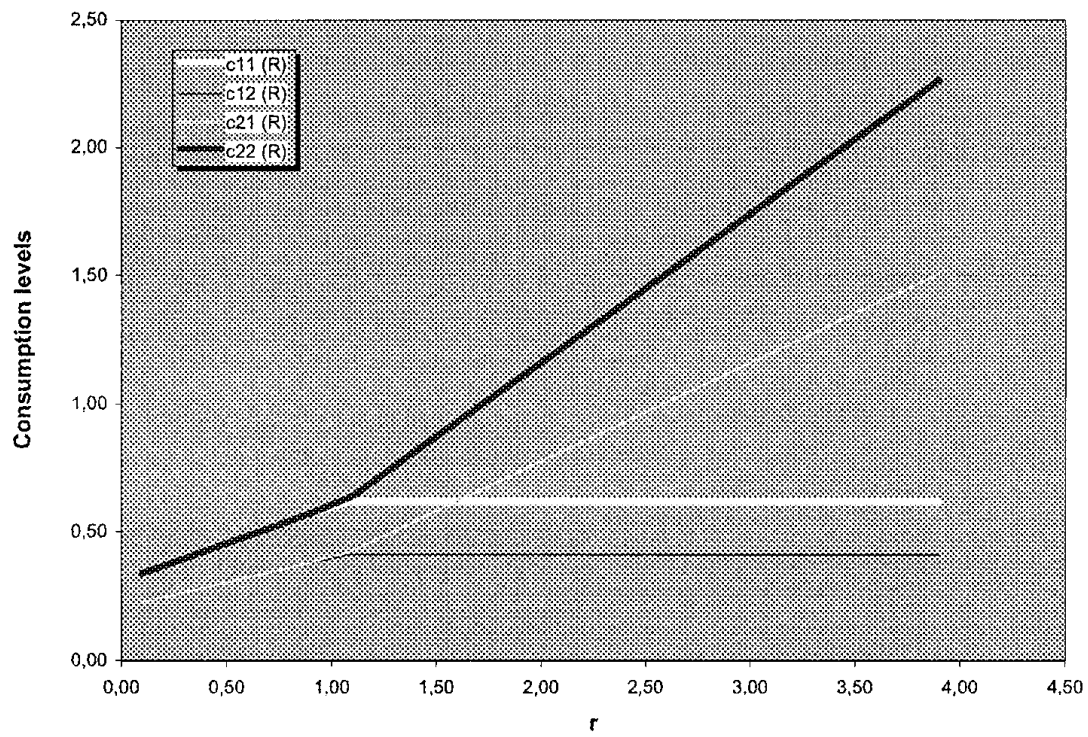

\begin{tabular}{|c|c|c|c|c|c|c|c|}
\hline t & Pt & $\rho$ & Rmin & $\mathrm{Rmax}$ & 1 & 82 & $\mathrm{EH}$ \\
\hline 0.50 & 0.60 & 0.40 & 0.00 & 4.00 & 0.52 & 0.48 & $-0,376$ \\
\hline
\end{tabular}

\begin{tabular}{|c|c|c|c|c|c|}
\hline $\mathrm{R}$ & r & c1 & $c_{1}$ & $\mathrm{c}_{4}$ & $c_{22}$ \\
\hline 0,100 & 0,094 & 0,339 & 0,226 & 0,226 & 0,339 \\
\hline 0,300 & 0,281 & 0,397 & 0.265 & 0,265 & 0,397 \\
\hline 0,500 & 0,468 & 0,455 & 0,303 & 0,303 & 0,455 \\
\hline 0,700 & 0,656 & 0,513 & 0,342 & 0,342 & 0,513 \\
\hline 0,900 & 0,843 & 0,571 & 0.381 & 0,381 & 0,571 \\
\hline 1,100 & 1,030 & 0,620 & 0,413 & 0,426 & 0,638 \\
\hline 1,300 & 1,218 & 0,620 & 0,413 & 0,503 & 0,754 \\
\hline 1,500 & 1,405 & 0,620 & 0,413 & 0,580 & 0,871 \\
\hline 1,700 & 1,592 & 0,620 & 0,413 & 0,658 & 0,987 \\
\hline 1,900 & 1,780 & 0,620 & 0,413 & 0,735 & 1,103 \\
\hline 2,100 & 1,967 & 0,620 & 0,413 & 0,813 & 1,219 \\
\hline 2,300 & 2,154 & 0,620 & 0,413 & 0,890 & 1,335 \\
\hline 2,500 & 2,342 & 0,620 & 0,413 & 0,967 & 1,451 \\
\hline 2,700 & 2,529 & 0,620 & 0,413 & 1,045 & 1,567 \\
\hline 2,900 & 2,716 & 0,620 & 0,413 & 1,122 & 1,683 \\
\hline 3,100 & 2,904 & 0,620 & 0,413 & 1,199 & 1,799 \\
\hline 3,300 & 3,091 & 0,620 & 0,413 & 1,277 & 1,915 \\
\hline 3,500 & 3,278 & 0,620 & 0,413 & 1,354 & 2,031 \\
\hline 3,700 & 3,465 & 0,620 & 0,413 & 1,432 & 2,147 \\
\hline 3,900 & 3,653 & 0,620 & 0,413 & 1,509 & 2,263 \\
\hline
\end{tabular}

Figure 1. Optimal consumption levels in the first best allocation. 
That is, at $T=0$ or ex-ante period, individuals deposit their $k_{0}$ units of endowment in the bank and are offered a menu of contracts, where they receive a fixed payment at date 1 and a random one at date 2 . The second period random payment will depend on the random return $\tilde{R}$. This uncertain second period return reflects the fact that having invested in a risky asset the bank may not be able to make its promised payments at date 2. In this situation, when the bank is restricted to use a standard contract, bank runs will become a possibility. It will be denoted by $0 \leq \alpha(R) \leq t_{2}$ the fraction of type- 2 agents that choose to run, or equivalently, that demand the type-1 contract when the value of $R$ becomes sufficiently small (that is, when their incentive compatibility constraint is no longer satisfied). Let $\alpha(R)$ be defined as follows:

$$
\alpha(R) \begin{cases}=0 & \text { if }(1-\rho) \ln c_{12}(R)+\rho \ln c_{22}(R) \geq(1-\rho) \ln \left[\delta_{2} c_{11}(R)\right] \\ & \quad+\rho \ln \left[\left(1-\delta_{2}\right) c_{11}(R)+c_{21}(R)\right] \\ >0 & \text { otherwise }\end{cases}
$$

Whenever a run occurs all available funds will be divided pro rata in proportion to claims (as in Allen and Gale [1998], we do not assume a sequential service constraint).

The bank chooses a portfolio $k_{1}, k_{2}$, the consumption functions $c_{1 j}(R), c_{2 j}(R)(j=1,2)$, the deposit parameters $\bar{c}_{1 j}, \bar{c}_{2 j}$ and the withdrawal function $\alpha(R)$ that maximizes the following expression:

$$
\begin{array}{ll}
\max \left\{E_{\tilde{R}}\left[t_{1} U^{1}\left(c_{11}(R), c_{21}(R), \rho_{1}\right)+t_{2} U^{2}\left(c_{12}(R), c_{22}(R), \rho_{2}\right)\right]\right\} \\
\text { s.t. } \quad k_{1}+k_{2} \leq k_{0} \\
{\left[t_{1}+\alpha(R)\right] c_{11}(R)+\left[t_{2}-\alpha(R)\right] c_{12}(R) \leq k_{1}} \\
{\left[t_{1}+\alpha(R)\right]\left(c_{21}(R)+c_{11}(R)\right)+\left[t_{2}-\alpha(R)\right]\left[c_{22}(R)+c_{12}(R)\right]} \\
\leq k_{1}+k_{2} R \\
\forall 0 \leq \delta_{2} \leq 1 \\
\quad(1-\rho) \ln c_{12}(R)+\rho \ln c_{22}(R) \geq(1-\rho) \ln \left[\delta_{2} c_{11}(R)\right] \\
\quad+\rho \ln \left[\left(1-\delta_{2}\right) c_{11}(R)+c_{21}(R)\right] \\
\forall 0 \leq \delta_{1} \leq 1 \\
\quad \rho \ln c_{11}(R)+(1-\rho) \ln c_{21}(R) \\
\quad \geq \rho \ln \left[\delta_{1} c_{12}(R)\right]+(1-\rho) \ln \left[\left(1-\delta_{1}\right) c_{12}(R)+c_{22}(R)\right] \\
\text { if } 0<\alpha(R)<t_{2} \\
\quad(1-\rho) \ln c_{12}(R)+\rho \ln c_{22}(R) \\
\quad=(1-\rho) \ln \left[\delta_{2} c_{11}(R)\right]+\rho \ln \left[\left(1-\delta_{2}\right) c_{11}(R)+c_{21}(R)\right] \\
\text { if } c_{11}(R)<\overline{c_{11}} \\
\quad\left[t_{1}+\alpha(R)\right] c_{11}(R)+\left[t_{2}-\alpha(R)\right] c_{12}(R) \leq k_{1} \\
c_{1 j}(R) \leq \overline{c_{1 j}} \\
0 \leq \alpha(R) \leq t_{2}
\end{array}
$$


Constraints (a) to (e) are familiar. Constraint (a) states that the total amount invested must be less or equal to the amount deposited. Constraint (b) says that the investment in the safe asset should be enough to cover consumption at date 1 . The constraint takes into account the fact that some type- 2 agents may choose to run, that is, to demand the type- 1 contract. Whenever there is a run, type-1 depositors will not be able to receive their promised payment $\left(\overline{c_{11}}\right)$ and so their final consumption $\left(c_{11}(R)\right)$ will depend on the proportion of type-2 depositors that choose to run. This means that $c_{11}(R)=\overline{c_{11}}$ if $\alpha(R)=0$, and $c_{11}(R)<$ $\overline{c_{11}}$ otherwise. Constraint (c) states that the investment in the risky asset plus the amount of the safe one that is left over from period one should be enough to cover consumption at date 2 . Similarly, the constraint takes into account the fact that type- 2 agents may choose to run. Constraints (d) and (e) are the incentive compatibility constraints. ${ }^{13}$ Finally, constraints (f) and (g) deserve some explanation. As mentioned above, the bank offers individuals a fixed payment at date 1 and a random one at date 2 . If this random second period return is sufficiently high, the contract is incentive compatible, that is, type- 2 agents always prefer their allocation to the possibility of receiving the type- 1 allocation and using the storage technology. However, there is a critical value of $R,{ }^{14}$ below which the contract is no longer incentive compatible and some or all type- 2 agents will decide to run on the bank. These withdrawals will stop when the utility of the two groups is equated or equivalently, when the incentive compatibility constraint for type- 2 agents is restored (constraint (f)). Whenever there are runs, and therefore type- 1 agents cannot receive their promised payment at date 1 $\left(\overline{c_{11}}\right)$, the bank "may"15 exhaust the liquid asset among depositors: type-1 and some type-2 that demand the type- 1 contract (and are treated on an equal basis) and other type- 2 that demand their promised payment at date 1 . However, in some cases the bank will find it optimal to suspend payments (that is, not exhaust the liquid asset when runs occur). This is represented by constraint ( $\mathrm{g}$ ).

It is implicitly assumed that those type- 2 agents that demand the type- 1 contract can use the storage technology, and smooth consumption in the optimal way for them, and so in equilibrium their consumption will be the same as the rest of the type- 2 agents.

The solution to the bank's problem defined above is given by the following theorem:

Theorem 2: The solution $\left[k_{1}, k_{2}, \overline{c_{1 j}}, c_{1 j}(R), c_{2 j}(R), \alpha(R)\right](j=1,2)$, to the bank's problem is characterized by the following conditions:

Demand deposit contract

$$
\begin{aligned}
\overline{c_{11}} & =\frac{1}{1+\mu} \frac{k_{1}}{t_{1 m}} \quad \overline{c_{12}}=\mu \overline{c_{11}} \\
c_{22}(R) & =r \overline{c_{11}} \quad c_{21}(R)=\mu c_{22}(R) \\
\text { if } r \leq r_{1}=\mu \frac{t_{1 m}}{t_{2 m}}(\text { case } 3): & \\
c_{11}(R) & =c_{22}(R)=\frac{1}{1+\mu} \frac{k_{1}}{t_{1 m}}\left[t_{1 m}+r t_{2 m}\right] \\
c_{21}(R) & =c_{12}(R)=\frac{\mu}{1+\mu} \frac{k_{1}}{t_{1 m}}\left[t_{1 m}+r t_{2 m}\right] \\
\alpha(R) & =t_{2}
\end{aligned}
$$




$$
\text { if } \left.r_{1}<r<1 \text { (case } 2\right) \text { : }
$$

$$
\begin{aligned}
c_{11}(R) & =c_{22}(R)=\frac{k_{1}}{t_{1}+\alpha(R)+\left(t_{2}-\alpha(R)\right) \mu} \\
c_{12}(R) & =c_{21}(R)=\mu c_{11}(R) \\
\alpha(R) & =\frac{1}{2} \frac{1+\mu}{1-\mu}\left[t_{2 m}-t_{1 m}+\frac{t_{1 m}-t_{2 m} r}{t_{1 m}+t_{2 m} r}\right]<t_{2}
\end{aligned}
$$

if $r \geq 1$ (case 1$)$ :

$$
\begin{aligned}
& c_{11}(R)=\overline{c_{11}} \quad c_{12}(R)=\overline{c_{12}} \\
& c_{22}(R)=r \overline{c_{11}} \quad c_{21}(R)=r \overline{c_{22}} \\
& \alpha(R)=0
\end{aligned}
$$

and $k_{1}, k_{2}$, the values that maximize the following expression:

$$
\begin{aligned}
& \max _{k_{1}, k_{2}}\left[\int_{0}^{r 1} U^{*(1)} f(r) d r \frac{t_{2 m}}{t_{1 m}} \frac{k_{1}}{k_{2}}+\int_{r 1}^{1} U^{*(2)} f(r) d r \frac{t_{1 m}}{t_{2 m}} \frac{k_{1}}{k_{2}}\right. \\
& \left.\quad+\int_{1}^{\infty} U^{*(3)} f(r) d r \frac{t_{1 m}}{t_{2 m}} \frac{k_{1}}{k_{2}}\right] \\
& \text { s.t } \quad k_{1}+k_{2}=k_{0}
\end{aligned}
$$

Proof. See Appendix C for a detailed resolution of the problem.

As mentioned above, the bank offers individuals a standard contract, where they receive a fixed payment at date 1 and a random one at date 2 . This contract corresponds to case 2 of Theorem 1 and it is incentive compatible as long as $r \geq 1$. Therefore for values of $r \geq 1$ there are no bank runs and individuals will consume what was planned ex-ante by the bank. The consumption levels are given by case 1 of Theorem 2. For values of $r<1$ there are partial or total bank runs and the consumption levels are those given by cases 2 and 3 of Theorem 2.

The optimal consumption levels are illustrated in figure 2, for the parameter values of the example. It can be observed that for values of $r \leq r_{1}=0.66$ bank runs involve all type 2 agents, and the consumption levels are those given by case 3 of Theorem 2. It should be mentioned that in the case in which there are total bank runs the bank does not exhaust the liquid asset among depositors.

For $0.66<r<1$, bank runs will be partial and the consumption levels are those given by case 2 . Finally, when $r \geq 1$, there are no bank runs and individuals will consume what was planned by the bank, as given by case 1 .

If we compare the optimal consumption functions for the two problems, it can be seen that both solutions coincide. However, in order to implement the optimal solution, the bank must restrict payments at date 1 , when the long term return is very bad. This result is expressed by the following theorem: 


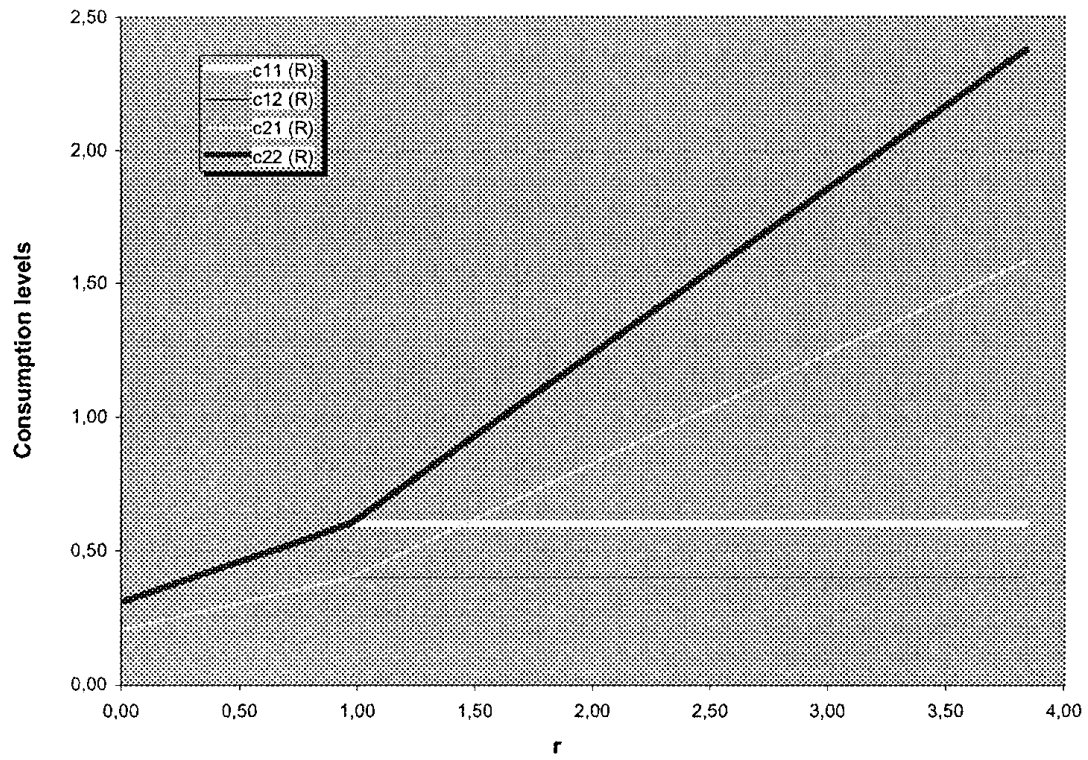

\begin{tabular}{|c|c|c|c|c|c|c|c|}
\hline 1 & $P_{1}$ & $\rho_{2}$ & Rmin & $\mathrm{Rmax}$ & 81 & $k 2$ & $\mathrm{Eu}$ \\
\hline 0.50 & 0.60 & 0.40 & 0.00 & 4.00 & 0.52 & 0.48 & -0.376 \\
\hline
\end{tabular}

\begin{tabular}{|c|c|c|c|c|c|c|}
\hline h & 1 & $a$ & 0 & 812 & $G_{21}$ & 6 \\
\hline 0,100 & 0,096 & 0,500 & 0,339 & 0,226 & 0,226 & 0,339 \\
\hline 0,300 & 0,289 & 0,500 & 0,397 & 0,265 & 0,265 & 0,397 \\
\hline 0,500 & 0,481 & 0,500 & 0,455 & 0,303 & 0,303 & 0,455 \\
\hline 0,700 & 0,674 & 0.487 & 0,512 & 0,341 & 0,341 & 0,512 \\
\hline 0,900 & 0,866 & 0,179 & 0,571 & 0,380 & 0,380 & 0.571 \\
\hline 1,100 & 1,059 & 0,000 & 0,611 & 0,408 & 0,432 & 0,647 \\
\hline 1,300 & 1,251 & 0.000 & 0,611 & 0,408 & 0,510 & 0,765 \\
\hline 1,500 & 1,444 & 0,000 & 0,611 & 0,408 & 0,589 & 0,883 \\
\hline 1,700 & 1,636 & 0,000 & 0,611 & 0,408 & 0,667 & 1,001 \\
\hline 1,900 & 1,829 & 0,000 & 0,611 & 0,408 & 0,746 & 1,118 \\
\hline 2,100 & 2,022 & 0,000 & 0,611 & 0,408 & 0,824 & 1,236 \\
\hline 2,300 & 2,214 & 0,000 & 0,611 & 0,408 & 0,902 & 1,354 \\
\hline 2,500 & 2,407 & 0,000 & 0,611 & 0,408 & 0,981 & 1,471 \\
\hline 2,700 & 2,599 & 0,000 & 0,611 & 0,408 & 1,059 & 1,589 \\
\hline 2,900 & 2,792 & 0,000 & 0,611 & 0,408 & 1,138 & 1,707 \\
\hline 3,100 & 2,984 & 0.000 & 0,611 & 0,408 & 1,216 & 1,825 \\
\hline 3,300 & 3,177 & 0,000 & 0,611 & 0,408 & 1,295 & 1,942 \\
\hline 3,500 & 3,369 & 0,000 & 0,611 & 0,408 & 1,373 & 2,060 \\
\hline 3,700 & 3,562 & 0,000 & 0,611 & 0,408 & 1,452 & 2,178 \\
\hline 3,900 & 3,754 & 0,000 & 0,611 & 0,408 & 1,530 & 2,295 \\
\hline
\end{tabular}

Figure 2. Optimal consumption levels with the standard contract. 
Theorem 3: Assuming the support of $R$ contains zero, then a banking system subject to runs cannot achieve first-best efficiency using a standard contract unless a suspension of convertibility policy is adopted.

Proof. As mentioned above, the bank offers individuals a standard contract which cannot be made contingent on the risky return. For values of the specific return higher or equal to one $(r \geq 1)$, the contract is incentive compatible and there are no runs $(\alpha(R)=0)$. In this case, the consumption functions coincide with those obtained in the first best case (case 2 of Theorem 1). For values of the specific return $r_{1}<r<1$, the contract is no longer incentive compatible and there would be partial bank runs, involving only a fraction of type- 2 consumers $\left(0<\alpha(R)<t_{2}\right)$. It can be shown that substituting this value $\alpha(R)$, in the expression for $c_{11}(R)$ corresponding to this case, it is obtained that $c_{11}(R)=\frac{1}{1+\mu} \frac{k_{1}}{t_{1 m}}\left[t_{1 m}+\right.$ $\left.r t_{2 m}\right]$ and again these consumption functions coincide with the ones obtained in the first best case (case 1 of Theorem 1). Finally, for very low values of the specific return, $r \leq r_{1}$, all type-2 agents will decide to run on the bank $\left(\alpha(R)=t_{2}\right)$. In this case, the bank can implement the first best allocation by suspending payments at date 1 . This is the main difference with respect to Allen and Gale's results. In their case, due to the corner preference assumption, bank runs were always partial. As long as there is a positive value of the risky asset, there must be a positive fraction of late consumers who wait until the last period, (p. 1259). ${ }^{16}$

In the numerical example the optimal levels of the initial investments are $k_{1}^{*}=0.52$ and $k_{2}^{*}=0.48$ and the expected utility achieved with a standard contract is -0.3757 .

The above result shows that Theorem 2 of Allen and Gale's paper is not robust, and therefore, it provides a rationale for banking regulation. In this sense, a suspension of convertibility policy, that restricts payments at date 1 , would implement the first-best. Payments in the first period would be restricted to a level of $\bar{k}<k_{1}$, where $\bar{k}=\frac{1}{1+\mu} \frac{k_{1}}{t_{1 m}}\left[t_{1 m}+r t_{2 m}\right]{ }^{17}$

\section{Concluding remarks}

The motivation of this paper has been to show that Allen and Gale's result is not robust: In Theorem 2 of their paper they show that a standard demand deposit contract, which will lead to bank runs in some states of the world, achieves optimal risk sharing. However, if there are liquidation costs or markets for risky assets are introduced, then bank runs are no longer optimal. Allen and Gale consider a particular characterization of preferences, where the so called type- 1 depositors derive only utility for consumption in period 1 and type- 2 depositors derive utility for consumption in period 2 . This paper extends the above model by considering a more general, and realistic, preference structure, in which individuals derive utility for consumption in both periods of their lives, although type-1 agents derive relatively more utility for consumption in period 1 with respect to type- 2 agents. It is shown that in this more general framework, even if there are no liquidation costs, standard contracts and bank runs can never achieve the first best outcome, unless a suspension of convertibility policy is implemented.

The more general preference structure considered in the present work allows for total bank runs and this is the main difference with respect to Allen and Gale's model, where bank 
runs were always partial. In their case, as type- 1 agents received nothing at date 2 , being the only type- 2 to stay the course would give the investor infinite returns when the long-term asset return is close to zero. By contrast, in this model, as type- 1 agents are supposed to receive some cash at date 2 , the lone type- 2 simply obtains a somewhat larger share of a very small pie. Type- 2 agents are then better off by running on the bank. However, if all type- 2 agents run, they would consume too much at date 1 relatively to the first best. The bank can then suspend convertibility if the bank's return is very low, and this will reduce the amount of first period cash that type- 2 individuals obtain by imitating type- $1 \mathrm{~s}$ to the point to which they are willing to follow the type-2 plan.

The contribution of the paper is in this sense to show that there are no positive aspects to a crisis, that is, bank runs are always costly and should be prevented with regulation.

\section{Appendix A: Incentive compatibility constraints}

In the optimal incentive risk-sharing problem defined in Subsection 2.1, it is assumed that the realization of the timing of the consumption needs is private information of the consumer. Given this information asymmetry, an allocation can only be implemented if it is incentive compatible, that is, if it gives no consumer an incentive to lie or deviate about what he actually wants to consume. In the case of a type 2 agent, incentive compatibility requires that the utility obtained from the consumption bundle he receives if he is honest $\left(c_{12}(R), c_{22}(R)\right)$, should be at least as large as the utility obtained by lying and behaving like a type 1 agent, that is, obtaining the consumption bundle $\left(c_{11}(R), c_{21}(R)\right)$ and then reinvesting his first period consumption in the storage technology in the optimal way for him. If he reinvested part of his first period allocation $\left(c_{11}(R)\right)$ in this storage technology, his optimal consumption levels in both periods $c_{1}^{* 2}(R), c_{2}^{* 2}(R)$ are the solution to the following problem:

$$
\begin{array}{ll}
\max _{c_{1}(R) \cdot c_{2}(R)}\left\{(1-\rho) \ln c_{1}(R)+\rho \ln c_{2}(R)\right\} \\
\text { s.t. } \quad c_{1}(R) \leq c_{11}(R) \\
\quad c_{2}(R)=\left(c_{11}(R)-c_{1}(R)\right)+c_{21}(R)
\end{array}
$$

which yields:
(a) $c_{1}^{* 2}(R)=c_{11}(R)$
$c_{2}^{* 2}(R)=c_{22}(R)$
if $\mu>\frac{c_{11}(R)}{c_{21}(R)}$
(b) $\quad c_{1}^{* 1 \mu}(R)=\frac{\left(c_{11}(R)+c_{21}(R)\right) \mu}{1+\mu}$
$c_{2}^{* 2}(R)=\frac{c_{11}(R)+c_{21}(R)}{1+\mu}$
if $\mu \leq \frac{c_{11}(R)}{c_{21}(R)}$

The incentive compatibility constraint for a type-2 agent is then:

$$
(1-\rho) \ln c_{12}(R)+\rho \ln c_{22}(R) \geq(1-\rho) \ln c_{1}^{* 2}(R)+\rho \ln c_{2}^{* 2}(R)
$$

The incentive compatibility constraint for a type-1 agent is obtained in a similar way, and would be:

$$
\rho \ln c_{11}(R)+(1-\rho) \ln c_{21}(R) \geq \rho \ln c_{1}^{* 1}(R)+(1-\rho) \ln c_{2}^{* 1}(R)
$$


where
(a) $c_{1}^{* 1}(R)=c_{12}(R)$
$c_{2}^{* 1}(R)=c_{22}(R)$
if $\mu<\frac{c_{22}(R)}{c_{12}(R)}$
(b) $c_{1}^{* 1}(R)=\frac{c_{12}(R)+c_{22}(R)}{1+\mu}$
$c_{2}^{* 1}(R)=\frac{\left(c_{12}(R)+c_{22}(R)\right) \mu}{1+\mu} \quad$ if $\mu \geq \frac{c_{22}(R)}{c_{12}(R)}$

\section{Appendix B: Optimal incentive compatible risk-sharing problem}

The first best allocation is obtained as a solution to the following problem:

$$
\begin{array}{ll}
\max _{c_{i j}, k_{1} k_{2}} & \left\{E_{\tilde{R}}\left[t_{1} U^{1}\left(c_{11}(R), c_{21}(R), \rho_{1}\right)+t_{2} U^{2}\left(c_{12}(R), c_{22}(R), \rho_{2}\right)\right]\right\} \\
\text { s.t. } & k_{1}+k_{2} \leq k_{0} \\
& t_{1} c_{11}(R)+t_{2} c_{12}(R) \leq k_{1} \\
& t_{1}\left[c_{21}(R)+c_{11}(R)\right]+t_{2}\left[c_{22}(R)+c_{12}(R)\right] \leq k_{1}+k_{2} R \\
(1-\rho) \ln c_{12}(R)+\rho \ln c_{22}(R) \geq(1-\rho) \ln c_{1}^{* 2}(R)+\rho \ln c_{2}^{* 2}(R) \\
\rho \ln c_{11}(R)+(1-\rho) \ln c_{21}(R) \geq \rho \ln c_{1}^{* 1}(R)+(1-\rho) \ln c_{2}^{* 1}(R)
\end{array}
$$

and where $c_{i}^{* j},(i, j=1,2)$ were defined in the previous section. However, in solving the optimal risk-sharing problem the incentive compatibility constraints can be dispensed with. The problem is solved subject to the three constraints and it can be shown that the first-best solution is always incentive compatible. For each value of $R$ the consumption levels $c_{i j}(R)$ solve the problem:

$$
\begin{array}{ll}
\max _{c_{i j}, k_{1} k_{2}}\left\{E_{\tilde{R}}\left[t_{1} U^{1}\left(c_{11}(R), c_{21}(R), \rho_{1}\right)+t_{2} U^{2}\left(c_{12}(R), c_{22}(R), \rho_{2}\right)\right]\right\} \\
\text { s.t. } & t_{1} c_{11}(R)+t_{2} c_{12}(R) \leq k_{1} \\
& t_{1}\left[c_{21}(R)+c_{11}(R)\right]+t_{2}\left[c_{22}(R)+c_{12}(R)\right] \leq k_{1}+k_{2} R
\end{array}
$$

The Lagrangian is formed by using the lagrangian multipliers $\lambda_{1}$ and $\lambda_{2}$ of the first two resource constraints.

The Kuhn-Tucker conditions are:

$$
\begin{array}{lll}
t_{1} \rho \frac{1}{c_{11}(R)}-\lambda_{1} t_{1}-t_{1} \lambda_{2}=0 & \text { if } c_{11}(R)>0 & \text { (a) } \\
t_{1}(1-\rho) \frac{1}{c_{21}(R)}-t_{1} \lambda_{2}=0 & \text { if } c_{21}(R)>0 & \text { (b) } \\
t_{2}(1-\rho) \frac{1}{c_{12}(R)}-\lambda_{1} t_{2}-t_{2} \lambda_{2}=0 & \text { if } c_{12}(R)>0 & \text { (c) } \\
t_{2} \rho \frac{1}{c_{22}(R)}-t_{2} \lambda_{2}=0 & \text { if } c_{22}(R)>0 & \text { (d) } \\
k_{1}-t_{1} c_{11}(R)-t_{2} c_{12}(R)=0 & \text { if } \lambda_{1}>0 & \text { (e) } \\
k_{1}+k_{2} R-t_{1}\left[c_{11}(R)+c_{21}(R)\right]-t_{2}\left[c_{12}(R)\right. & & \\
\left.\quad+c_{22}(R)\right]=0 & \text { if } \lambda_{2}>0
\end{array}
$$


Let

$$
\mu=\frac{1-\rho}{\rho} ; \quad t_{1 m}=\frac{t_{1}+t_{2} \mu}{1+\mu} ; \quad t_{2} m=\frac{t_{2}+t_{1} \mu}{1+\mu}
$$

and

$$
r=R \frac{\left(k_{2} / k_{1}\right)}{\left(t_{2 m} / t_{1 m}\right)}
$$

This random variable $r$ is essential in defining the ex ante risk-sharing problem.

The following cases may be considered:

Case 1: $\left(\lambda_{1}=0\right)$

From Eqs. (32a) and (32c):

$$
c_{12}(R)=\mu c_{11}(R)
$$

From Eqs. (32b) and (32d):

$$
c_{21}(R)=\mu c_{22}(R)
$$

From Eqs. (32a) and (32d):

$$
c_{11}(R)=c_{22}(R)
$$

Substituting Eqs. (35)-(37) in Eq. (32f) the value of $c_{11}^{*}(R)$ is obtained. The optimal solution to this problem is then:

$$
\begin{aligned}
& c_{11}^{*}(R)=c_{22}^{*}(R)=\frac{1}{1+\mu} \frac{k_{1}}{t_{1 m}}\left[t_{1 m}+r t_{2 m}\right] \\
& c_{21}^{*}(R)=c_{12}^{*}(R)=\mu c_{11}^{*}(R)
\end{aligned}
$$

In this case it is assumed that $\lambda_{1}=0$, or equivalently:

$$
t_{1} c_{11}^{*}(R)+t_{2} c_{12}^{*}(R) \leq k_{1}
$$

Substituting $c_{11}^{*}(R)$ and $c_{12}^{*}(R)$ in the above expression, the following condition for this case to hold is obtained, that is, $t_{1 m}+r t_{2 m} \leq 1$ or equivalently $r \leq 1$.

Case 2: $\left(\lambda_{1}>0\right)$

From Eqs. (32a) and (32c):

$$
c_{12}(R)=\mu c_{11}(R)
$$


From Eqs. (32b) and (32d):

$$
c_{21}(R)=\mu c_{22}(R)
$$

Substituting Eq. (40) in (32e), the value of $c_{11}^{*}(R)$ is obtained.

Substituting Eq. (41) in (32f), the value of $c_{22}^{*}(R)$ is obtained.

The optimal solution is then:

$$
\begin{aligned}
& c_{11}(R)=\frac{1}{1+\mu} \frac{k_{1}}{t_{1 m}} \quad c_{12}(R)=\mu c_{11}(R) \\
& c_{22}(R)=r c_{11}(R) \quad c_{21}(R)=\mu c_{22}(R)
\end{aligned}
$$

In this case it is assumed $\lambda_{1}>0$, from [a] and [b]:

$$
\lambda_{1}=\rho \frac{1}{c_{11}^{*}(R)}-(1-\rho) \frac{1}{c_{11}^{*}(R)}>0
$$

Substituting the optimal consumption levels in the above expression we would obtain that this case holds for $r>1$.

Finally, it remains to be shown that the optimal solution is incentive compatible.

Case $1(r \leq 1)$ : The incentive constraints are those given by Eqs. (24) and (25), where $c_{i}^{* j}(R)(i, j=1,2)$ correspond to those given by Eqs. (23b) and (26a). ${ }^{18}$

The incentive constraint for type- 2 agents is then:

$$
(1-\rho) \ln c_{12}^{*}(R)+\rho \ln c_{22}^{*}(R) \geq(1-\rho) \ln \mu c_{11}^{*}(R)+\rho \ln c_{11}^{*}(R)
$$

or equivalently, substituting the optimal consumption levels in the above equation:

$$
\ln c_{11}^{*}(R)+(1-\rho) \ln \mu \geq \ln c_{11}^{*}(R)+(1-\rho) \ln \mu
$$

The incentive constraint for type-1 agents is:

$$
\rho \ln c_{11}^{*}(R)+(1-\rho) \ln c_{21}^{*}(R) \geq \rho \ln \mu c_{11}^{*}(R)+(1-\rho) \ln c_{11}^{*}(R)
$$

or equivalently,

$$
\ln c_{11}^{*}(R)+(1-\rho) \ln \mu \geq \ln c_{11}^{*}(R)+\rho \ln \mu
$$

i.e.

$$
(1-\rho) \leq \rho
$$

And so in case 1 the optimal allocation is always incentive compatible. 
Case $2(r>1)$ : The incentive compatibility constraints are again (24) and (25). In this case, $c_{i}^{* j}$ correspond to those given by Eq. (23a) if $r>1 / \mu^{2}$ and (23b) if $r \leq 1 / \mu^{2}$ and (26a). ${ }^{19}$

The incentive constraint for type-2 agents, with (23a):

$$
(1-\rho) \ln c_{12}^{*}(R)+\rho \ln c_{22}^{*}(R) \geq(1-\rho) \ln c_{11}^{*}(R)+\rho \ln \mu r c_{11}^{*}(R)
$$

substituting the optimal consumption levels in this case we obtain:

$$
(1-\rho) \ln \mu c_{11}^{*}(R)+\rho \ln r c_{11}^{*}(R) \geq(1-\rho) \ln c_{11}^{*}(R)+\rho \ln \mu r c_{11}^{*}(R)
$$

or equivalently,

$$
\ln c_{11}^{*}(R)+(1-\rho) \ln \mu+\rho \ln r \geq \ln c_{11}^{*}(R)+\rho \ln \mu r
$$

i.e.

$$
1-\rho \leq \rho
$$

The incentive constraint for type- 2 agents, with (23b) is:

$$
(1-\rho) \ln c_{12}^{*}(R)+\rho \ln c_{22}^{*}(R) \geq(1-\rho) \ln \frac{1+\mu r}{1+\mu} \mu c_{11}^{*}(R)+\rho \ln \frac{1+\mu r}{1+\mu} c_{11}^{*}(R)
$$

substituting the optimal consumption levels in the above equation we obtain:

$$
(1-\rho) \ln \mu c_{11}^{*}(R)+\rho \ln r c_{11}^{*}(R) \geq(1-\rho) \ln \frac{1+\mu r}{1+\mu} \mu c_{11}^{*}(R)+\rho \ln \frac{1+\mu r}{1+\mu} c_{11}^{*}(R)
$$

or equivalently,

$$
\ln c_{11}^{*}(R)+(1-\rho) \ln \mu+\rho \ln r \geq(1-\rho) \ln \mu+\ln \frac{1+\mu r}{1+\mu}+\ln c_{11}^{*}(R)
$$

i.e.

$$
r^{\rho} \geq \frac{1+\mu r}{1+\mu}
$$

The above inequality is strictly satisfied if $r=1$ and is completely fulfilled for $r>1$. This implies that $r$ should be $\geq 1$.

Finally, the incentive constraint for type-1 agents:

$$
\rho \ln c_{11}^{*}(R)+(1-\rho) \ln c_{21}^{*}(R) \geq \rho \ln \mu c_{11}^{*}(R)+(1-\rho) \ln r c_{11}^{*}(R)
$$

or equivalently,

$$
\rho \ln c_{11}^{*}(R)+(1-\rho) \ln \mu r c_{11}^{*}(R) \geq \ln c_{11}^{*}(R)+\rho \ln \mu+(1-\rho) \ln r
$$


i.e.

$$
(1-\rho) \leq \rho
$$

In a second step the values $k_{1}, k_{2}$, are obtained by maximizing the following expression:

$$
\begin{aligned}
& \max _{k_{1}, k_{2}}\left\{\int_{0}^{1} U^{*(1)} f(r) d r \frac{t_{2 m}}{t_{1 m}} \frac{k_{1}}{k_{2}}+\int_{1}^{\infty} U^{*(2)} f(r) d r \frac{t_{2 m}}{t_{1 m}} \frac{k_{1}}{k_{2}}\right\} \\
& \text { s.t. } \quad k_{1}+k_{2}=k_{0}
\end{aligned}
$$

where $U^{*(1)}$ and $U^{*(2)}$ are the utility functions corresponding to the cases $r \leq 1$ and $r>1$ respectively.

\section{Appendix C: Optimal risk-sharing through deposit contracts with bank runs}

The bank chooses a portfolio $k_{1}, k_{2}$, the consumption functions $c_{1 j}(R), c_{2 j}(R)(j=1,2)$, the demand deposit contract and the withdrawal function $\alpha(R)$ that maximizes the following expression:

$$
\begin{array}{ll}
\max \left\{E_{\tilde{R}}\left[t_{1} U^{1}\left(c_{11}(R), c_{21}(R), \rho_{1}\right)+t_{2} U^{2}\left(c_{12}(R), c_{22}(R), \rho_{2}\right)\right]\right\} \\
\text { s.t. } \quad k_{1}+k_{2} \leq k_{0} \\
\quad\left[t_{1}+\alpha(R)\right] c_{11}(R)+\left[t_{2}-\alpha(R)\right] c_{12}(R) \leq k_{1} \\
\quad\left[t_{1}+\alpha(R)\right]\left(c_{21}(R)+c_{11}(R)\right)+\left[t_{2}-\alpha(R)\right]\left[c_{22}(R)+c_{12}(R)\right] \\
\quad \leq k_{1}+k_{2} R \\
(1-\rho) \ln c_{12}(R)+\rho \ln c_{22}(R) \geq(1-\rho) \ln c_{1}^{* 2}(R)+\rho \ln c_{2}^{* 2}(R) \\
\rho \ln c_{11}(R)+(1-\rho) \ln c_{21}(R) \geq \rho \ln c_{1}^{* 1}(R)+(1-\rho) \ln c_{2}^{* 1}(R) \\
\text { if } \alpha(R)>0 \\
\quad(1-\rho) \ln c_{12}(R)+\rho \ln c_{22}(R) \\
\quad=(1-\rho) \ln c_{1}^{* 2}(R)+\rho \ln c_{2}^{* 2}(R) \\
\text { if } c_{11}(R)<\overline{c_{11}} \\
\quad\left[t_{1}+\alpha(R)\right] c_{11}(R)+\left[t_{2}-\alpha(R)\right] c_{12}(R) \leq k_{1} \\
c_{1 j}(R) \leq \overline{c_{1 j}} \\
0 \leq \alpha(R) \leq t_{2}
\end{array}
$$$$
\left[t_{1}+\alpha(R)\right]\left(c_{21}(R)+c_{11}(R)\right)+\left[t_{2}-\alpha(R)\right]\left[c_{22}(R)+c_{12}(R)\right]
$$$$
\rho \ln c_{11}(R)+(1-\rho) \ln c_{21}(R) \geq \rho \ln c_{1}^{* 1}(R)+(1-\rho) \ln c_{2}^{* 1}(R)
$$

and where $c_{i}^{* j},(i, j=1,2)$ were defined in Appendix A.

We solve the problem by parts:

(i) if there are no bank runs, that is, $\alpha(R)=0$, the individuals would consume what was planned ex ante by the bank. In this case, $c_{i j}(R)=\overline{c_{i j}}$ and $c_{2 j}(R)=c_{2 j}(R)(j=1,2)$. The demand deposit contract is obtained by maximizing the expected utility of depositors subject 
to the following constraints:

$$
\begin{aligned}
t_{1} \overline{c_{11}}+t_{2} \overline{c_{12}} & =k_{1} \\
t_{1} c_{21}(R)+t_{2} c_{22}(R) & =k_{2} R
\end{aligned}
$$

and incentive compatibility (constraints (63d) and (63e)).

This problem corresponds to the one given by case 2 in Appendix B, with solution:

$$
\begin{aligned}
& c_{11}(R)=\frac{1}{1+\mu} \frac{k_{1}}{t_{1 m}} \quad c_{12}(R)=\mu c_{11}(R) \\
& c_{22}(R)=r c_{11}(R) \quad c_{21}(R)=\mu c_{22}(R)
\end{aligned}
$$

We know that this solutions is incentive compatible for type- 2 agents as long as $r \geq 1$, and therefore if $r \geq 1$ individuals consume what planned by the bank and therefore $\alpha(R)=0$. (ii) Partial bank runs: If $r_{1}<r<1$, there will be partial bank runs, as some type-2 agents will claim the type- 1 contract. As mentioned in the text, whenever there are runs, and type-1 individuals cannot receive their promised payment $\bar{c}_{11}$, the bank exhausts the liquid asset among depositors. This is represented by constraint (g). Also, these withdrawals will stop when the incentive compatibility constraint of type- 2 agents is restored again. This is represented by constraint (f). Consumption of individuals in each period would then be obtained by maximizing the expected utility (62) subject to the constraints:

$$
\begin{aligned}
& {\left[t_{1}+\alpha(R)\right] c_{11}(R)+\left[t_{2}-\alpha(R)\right] c_{12}(R)=k_{1}} \\
& {\left[t_{1}+\alpha(R)\right] c_{21}(R)+\left[t_{2}-\alpha(R)\right] c_{22}(R)=k_{2} R}
\end{aligned}
$$

and incentive compatibility constraints (63e) and (63f). ${ }^{20}$

The Kuhn-Tucker conditions are:

$$
\begin{array}{lll}
t_{1} \frac{1}{c_{11}(R)}+\lambda_{1}\left(t_{1}+\alpha(R)\right)-\lambda_{3} \frac{1+\mu}{c_{11}(R)+c_{21}(R)}=0 & \text { if } c_{11}(R)>0 & \text { (a) } \\
t_{1} \mu \frac{1}{c_{21}(R)}+\lambda_{2}\left(t_{1}+\alpha(R)\right)-\lambda_{3} \frac{1+\mu}{c_{11}(R)+c_{21}(R)}=0 & \text { if } c_{21}(R)>0 & \text { (b) } \\
t_{2} \mu \frac{1}{c_{12}(R)}+\lambda_{1}\left(t_{2}-\alpha\right)+\lambda_{3} \frac{\mu}{c_{12}}=0 & \text { if } c_{12}(R)>0 & \text { (c) } \\
t_{2} \frac{1}{c_{22}(R)}+\left(t_{2}-\alpha(R)\right) \lambda_{2}+\lambda_{3} \frac{1}{c_{22}(R)}=0 & \text { if } c_{22}(R)>0 & \text { (d) } \\
\lambda_{1}\left(\left(c_{11}(R)-c_{12}(R)\right)+\lambda_{2}\left(\left(c_{21}(R)-c_{22}(R)=0\right.\right.\right. & \text { if } \alpha(R)>0 \\
\left(t_{1}+\alpha(R)\right) c_{11}(R)+\left(t_{2}-\alpha(R)\right) c_{12}(R)-k_{1}=0 & \text { if } \lambda_{1}>0 \\
\left(t_{1}+\alpha(R)\right) c_{21}(R)+\left(t_{2}-\alpha(R)\right) c_{22}(R)-k_{1}-k_{2} R=0 & \text { if } \lambda_{2}>0 \\
\mu \ln c_{12}(R)+\ln c_{22}(R)-\mu \ln \left[\frac{\left(c_{11}(R)+c_{21}(R)\right) \mu}{1+\mu}\right] & & \text { (g) } \\
\quad-\ln \left[\frac{\left(c_{11}(R)+c_{21}(R)\right)}{1+\mu}\right]=0 & \text { if } \lambda_{3}>0 & \text { (h) }
\end{array}
$$


From Eqs. (67a) and (67c):

$$
\begin{aligned}
& \frac{t_{1}}{t_{1}+\alpha(R)} \frac{1}{c_{11}(R)}-\frac{t_{2}}{t_{2}-\alpha(R)} \frac{\mu}{c_{12}(R)} \\
& \quad-\lambda_{3}\left[\frac{1+\mu}{t_{1}+\alpha(R)} \frac{1}{c_{11}(R)+c_{21}(R)}+\frac{\mu}{t_{2}-\alpha} \frac{1}{c_{12}(R)}\right]=0
\end{aligned}
$$

From Eqs. (67b) and (67d):

$$
\begin{aligned}
& \frac{t_{2}}{t_{2}-\alpha(R)} \frac{1}{c_{22}(R)}-\frac{t_{1}}{t_{1}+\alpha(R)} \frac{\mu}{c_{21}(R)} \\
& \quad+\lambda_{3}\left[\frac{1+\mu}{t_{1}+\alpha(R)} \frac{1}{c_{11}(R)+c_{21}(R)}+\frac{1}{t_{2}-\alpha} \frac{1}{c_{22}(R)}\right]=0
\end{aligned}
$$

Eliminating $\lambda_{3}$ from the above equations:

$$
\begin{aligned}
& {\left[\frac{t_{1}}{t_{1}+\alpha(R)} \frac{1}{c_{11}(R)}-\frac{t_{2}}{t_{2}-\alpha(R)} \frac{\mu}{c_{12}(R)}\right]} \\
& \quad \times\left[\frac{1+\mu}{t_{1}+\alpha(R)} \frac{1}{c_{11}(R)+c_{21}(R)}+\frac{1}{t_{2}-\alpha(R)} \frac{1}{c_{22}(R)}\right] \\
& \quad+\left[\frac{t_{2}}{t_{2}-\alpha(R)} \frac{1}{c_{22}(R)}-\frac{t_{1}}{t_{1}+\alpha(R)} \frac{\mu}{c_{21}(R)}\right] \\
& \quad \times\left[\frac{1+\mu}{t_{1}+\alpha(R)} \frac{1}{c_{11}(R)+c_{21}(R)}+\frac{\mu}{t_{2}-\alpha(R)} \frac{1}{c_{12}(R)}\right]=0
\end{aligned}
$$

From Eqs. (67a) and (67b):

$$
\frac{t_{1}}{t_{1}+\alpha(R)}\left[\frac{1}{c_{11}(R)}-\frac{\mu}{c_{21}(R)}\right]+\lambda_{1}-\lambda_{2}=0
$$

From Eqs. (67c) and (67d):

$$
\lambda_{1} c_{12}(R)-\lambda_{2} \mu c_{22}(R)=0
$$

Equations (71), (72) and (67e) imply:

$$
\left|\begin{array}{ccc}
c_{11}-c_{12} & c_{21}-c_{22} & 0 \\
1 & -1 & \frac{t_{1}}{t_{1}+\alpha}\left[\frac{1}{c_{11}}-\frac{\mu}{c_{21}}\right] \\
c_{12} & -\mu c_{22} & 0
\end{array}\right|=0
$$

with solution:

$$
\left[\frac{1}{c_{11}(R)}-\frac{\mu}{c_{21}(R)}\right]\left\{\left[c_{11}(R)-c_{12}(R)\right] \mu c_{22}(R)+c_{12}(R)\left[c_{21}(R)-c_{22}(R)\right\}\right]=0
$$


Two possibilities may be considered:

$$
\begin{aligned}
& c_{21}=\mu c_{11} \\
& \left(c_{11}(R)-c_{12}(R)\right) \mu c_{22}(R)+c_{12}(R)\left(c_{21}(R)-c_{22}(R)\right)=0
\end{aligned}
$$

(a) $c_{21}=\mu c_{11}$

The following change of variables will be adopted: $c_{1}(R)=\frac{c_{12}(R)}{c_{11} R}$ and $c_{2}(R)=\frac{c_{21}(R)}{c_{22}(R)}$. Equations (67f)-(67h), and (70), would become:

$$
\begin{aligned}
& c_{11}(R)=\frac{k_{1}}{t_{1}+\alpha(R)+\left(t_{2}-\alpha(R)\right) c_{1}(R)} \\
& c_{22}(R)=\frac{k_{2} R}{\left(t_{1}+\alpha(R)\right) c_{2}(R)+t_{2}-\alpha(R)} \\
& c_{1}(R)^{\mu} c_{22}(R)=c_{11}(R) \mu^{\mu} \\
& {\left[\frac{t_{1}}{t_{1}+\alpha(R)}-\frac{t_{2}}{t_{2}-\alpha(R)} \frac{\mu}{c_{1}(R)}\right]\left[\frac{1}{t_{1}+\alpha(R)} \frac{1}{c_{11}(R)}+\frac{1}{t_{2}-\alpha(R)} \frac{1}{c_{22}(R)}\right]} \\
& \quad+\left[\frac{t_{2}}{t_{2}-\alpha(R)} \frac{1}{c_{22}(R)}-\frac{1}{t_{1}+\alpha(R)} \frac{1}{c_{11}(R)}\right]\left[\frac{1}{t_{1}+\alpha(R)}+\frac{\mu}{t_{2}-\alpha(R)} \frac{1}{c_{1}(R)}\right]=0
\end{aligned}
$$

On the other hand, taking into account Eqs. (77)-(80) can be rewritten as follows:

$$
\begin{aligned}
& c_{1}(R)^{\mu} r \frac{t_{2 m}}{t_{1 m}}\left[\frac{t_{1}+\alpha+\left(t_{2}-\alpha\right) c_{1}(R)}{\left(t_{1}+\alpha(R)\right) c_{2}(R)+t_{2}-\alpha}\right]=\mu^{\mu} \\
& {\left[\frac{t_{1}}{t_{1}+\alpha(R)}-\frac{t_{2}}{t_{2}-\alpha(R)} \frac{\mu}{c_{1}(R)}\right]\left[\frac{1}{k_{1}} \frac{t_{1}+\alpha(R)+\left(t_{2}-\alpha(R)\right) c_{1}(R)}{t_{1}+\alpha(R)}\right.} \\
& \left.\quad+\frac{1}{k_{2} R} \frac{\left(t_{1}+\alpha(R)\right) c_{2}(R)+t_{2}-\alpha(R)}{t_{2}-\alpha(R)}\right] \\
& \quad+\left[\frac{t_{2}}{t_{2}-\alpha(R)} \frac{\left(t_{1}+\alpha(R)\right) c_{2}(R)+t_{2}-\alpha(R)}{k_{2} R}\right]\left[\frac{1}{t_{1}+\alpha(R)}+\frac{\mu}{t_{2}-\alpha(R)} \frac{1}{c_{1}(R)}\right]=0
\end{aligned}
$$

Let $a=\frac{t_{2}-\alpha(R)}{t_{1}+\alpha(R)}$. Equations (81) and (82) can be rewritten as follows:

$$
\begin{aligned}
& {\left[t_{1}-\frac{t_{2} \mu}{a c_{1}(R)}\right]\left[\frac{1+a c_{1}(R)}{k_{1}}+\frac{1}{k_{2} R}\left(1+\frac{c_{2}(R)}{a}\right)\right]} \\
& \quad+\left[1+\mu \frac{1}{a c_{1}(R)}\right]\left[\frac{t_{2}}{k_{2} R}\left(\frac{c_{2}(R)}{a}+1\right)-\frac{t_{1}}{k_{1}}\left(1+a c_{1}(R)\right)\right]=0 \\
& c_{1}(R)^{\mu} r \frac{t_{2 m}}{t_{1 m}}\left[\frac{1+a c_{1}(R)}{c_{2}(R)+a}\right]=\mu^{\mu}
\end{aligned}
$$


or equivalently, the value of $a$ from the above equation is:

$$
a=\frac{c_{1}(R)^{\mu} r \frac{t_{2 m}}{t_{1 m}}-c_{2} \mu^{\mu}}{\mu^{\mu}-r \frac{t_{2 m}}{t_{1 m}} c_{1}(R)^{1+\mu}}
$$

Finally from Eq. (79) and the relationship $c_{21}=\mu c_{11}$ it is obtained:

$$
c_{2}(R)=\frac{c_{1}(R)^{\mu}}{\mu^{\mu-1}}
$$

Equations (85) and (86) can be substituted in Eq. (83), in order to have a non linear equation in $c_{1}(R)$.

It can be easily verified that the solution to the non linear equation yields $c_{1}(R)=\mu$.

From Eq. (86) the value of $c_{2}(R)$ is also obtained, that is, $c_{2}(R)=\mu$.

$c_{1}(R)=\mu=\frac{c_{12}}{c_{11}}$ or equivalently $c_{12}=\mu c_{11}$. On the other hand $c_{21}=\mu c_{12}$. This implies that $c_{21}=c_{12}$.

$c_{2}(R)=\mu=\frac{c_{21}}{c_{22}}$ or equivalently $c_{21}=\mu c_{22}$. This also implies that $c_{22}=c_{11}$.

The value of $\alpha(R)$ is obtained from the expression: $a=\frac{t_{2}-\alpha(R)}{t_{1}+\alpha(R)}$. That is, $\alpha(R)=\frac{t_{2}-a t_{1}}{1+a}$.

Given that $c_{1}(R)=c_{2}(R)=\mu$, the value of $a$ in Eq. (85) is expressed as follows:

$$
a=\frac{r \frac{t_{2 m}}{t_{1 m}}-\mu}{1-\mu r \frac{t_{2 m}}{t_{1 m}}}
$$

Substituting the value of $a$ given by Eq. (87) in the above expression for $\alpha(R)$ it is obtained:

$$
\alpha(R)=\frac{1}{2} \frac{1+\mu}{1-\mu}\left[t_{2 m}-t_{1 m}+\frac{t_{1 m}-t_{2 m} r}{t_{1 m}+t_{2 m} r}\right]<t_{2}
$$

From Eq. (77) the value of $c_{11}$ was:

$$
c_{11}(R)=\frac{k_{1}}{t_{1}+\alpha(R)+\left(t_{2}-\alpha(R)\right) c_{1}(R)}
$$

or equivalently,

$$
c_{11}(R)=\frac{k_{1}(1+a)}{1+a \mu}
$$

Substituting the value of $a$ given by Eq. (87) in the above expression it is obtained:

$$
c_{11}(R)=\frac{1}{1+\mu} \frac{k_{1}}{t_{1 m}}\left[t_{1 m}+r t_{2 m}\right]
$$

and $c_{22}(R)=c_{11}(R), c_{12}(R)=c_{21}(R)=\mu c_{11}(R)$ 
This solution coincides with the first best solution (Case 1) given by Eq. (42). Therefore the other possibility given by Eq. (76) does not have to be considered.

In this case it is assumed that $0<\alpha(R)<t_{2}$. This means that if $\alpha=\frac{t_{2}-a t_{1}}{1+a}=t_{2}$, there are total bank runs and all type 2 agents will claim the type- 1 contract. This will occur when $a=0$, or substituting the value of $a$ given by Eq. (87) when $r=\mu \frac{t_{1 m}}{t_{2 m}}=r_{1}{ }^{21}$

(iii) If $r \leq r_{1}$ all agents will run on the bank $\left(\alpha(R)=t_{2}\right)$ and so in this case the constraints would become:

$$
\begin{aligned}
c_{11}(R) & \leq k_{1} \\
c_{11}(R)+c_{21}(R) & \leq k_{1}+k_{2} R
\end{aligned}
$$

that with the incentive compatibility constraints (63d) and (63e) yield the optimal solution in this case:

$$
\begin{aligned}
& c_{11}(R)=c_{22}(R)=\frac{1}{1+\mu} \frac{k_{1}}{t_{1 m}}\left[t_{1 m}+r t_{2 m}\right] \\
& c_{21}(R)=c_{12}(R)=\frac{\mu}{1+\mu} \frac{k_{1}}{t_{1 m}}\left[t_{1 m}+r t_{2 m}\right]
\end{aligned}
$$

as in the first best case.

In this case, the bank does not exhaust the liquid asset and so the suspension level would be $\bar{k}=\frac{1}{1+\mu} \frac{k_{1}}{t_{1 m}}\left[t_{1 m}+r t_{2 m}\right]$.

In a second step, the optimal levels of the initial investments $\left(k_{1}, k_{2}\right)$ are the values that maximize the following expression:

$$
\max _{k_{1}, k_{2}}\left\{\int_{0}^{r_{1}} U^{*(1)} f(r) d r \frac{t_{2 m}}{t_{1 m}} \frac{k_{1}}{k_{2}}+\int_{r_{1}}^{1} U^{*(2)} f(r) d r \frac{t_{2 m}}{t_{1 m}} \frac{k_{1}}{k_{2}}+\int_{1}^{\infty} U^{*(3)} f(r) d r \frac{t_{2 m}}{t_{1 m}} \frac{k_{1}}{k_{2}}\right\}
$$

s.t. $\quad k_{1}+k_{2}=k_{0}$

\section{Acknowledgments}

This research is partially funded by the Spanish Ministry of Education and Culture, projects: PB97-0089 DGES and SEC 2001-1169. The author owes special thanks to Sudipto Bhattacharya, her PhD advisor at CORE, Sandro Brusco and seminar participants at the IX International Tor Vergata Financial Conference (Rome, 2000) and at the Workshop of Banking and Finance (University Miguel Hernandez in Alicante, 2000). Finally, the help and comments of the editor and of two anonymous referees are also acknowledged.

\section{Notes}

1. See Samartín [1997] for a detailed description of bank regulation in the US and Europe in the 20th century.

2. From 1930 to 1933 the number of bank failures in the US averaged over 2000 per year (see Miskhin [1995]).

3. It should be noticed that most deposit insurance systems in Europe were created in 1970s. 
4. In the model, panics runs may occur due to the fact that uninformed individuals condition their beliefs about the bank's long-term technology on the size of the withdrawal queue at the bank. If this size is large (due to a high liquidity shock only) they may nevertheless infer sufficiently adverse information to precipitate a bank run.

5. Another exception is Bhattacharya and Gale [1987] or a few other references mentioned in Allen and Gale [1998].

6. Allen and Gale [1998] follow the Diamond and Dybvig [1983] specification of preferences, in which individuals derive utility for consumption either in period 1 or period 2. However, as Jacklin [1987] has noted, this assumption on preferences has the feature that banks and equity contracts are equivalent risk sharing instruments, and therefore this rules out a positive role for a financial intermediary in the economy.

7. Notice that if the safe asset is completely exhausted for date 1 consumption the second and third constraints would become: $t_{1} c_{11}(R)+t_{2} c_{12}(R)=k_{1}$ and $t_{1} c_{21}(R)+t_{2} c_{22}(R)=k_{2} R$, respectively.

8. The incentive compatibility constraints are derived in more detail in Appendix A.

9. Logarithmic additive utility functions are shown to have the feature that the first best allocation is always incentive compatible. As described in Appendix B, Case 1 of Theorem 1 is always incentive compatible and Case 2 is incentive compatible as long as $r=R \frac{\left(k_{2} / k_{1}\right)}{\left(t_{2 m} / t_{1 m}\right)} \geq 1$.

10. In the numerical example, a triangular distribution for the variable $\tilde{R}$, between the two extreme values $\left(R_{\min }, R_{\max }\right)$, has been assumed.

11. See also Jacklin and Bhattacharya [1988] or Alonso [1996].

12. As already mentioned in the introduction, the main purpose of this paper is to show that Allen and Gale's result is not robust, that is, bank runs can never achieve optimal risk sharing if a more general preference structure is introduced in their paper. For this purpose, all the assumptions of their model (except for the corner preference one) are maintained, and in particular, the same specification for the bank's contract is considered: a standard contract that gives depositors fixed payments at each date.

13. See Appendix A for a detailed calculation of these constraints.

14. It is shown in Appendix $C$ that the critical value is when $r<1$.

15. Unlike Allen and Gale [1998], who exhaust the liquid asset among depositors, whenever a run takes place, we leave open the possibility of not exhausting first period resources, even if a run occurs. This could be interpreted as a suspension of convertibility policy.

16. It should be noticed that in Allen and Gale's case $r_{1}=\frac{t_{1 m}}{t_{2 m}}=0$ as $\mu=\frac{1-\rho}{\rho}=0$ and therefore bank runs are always partial.

17. It should be mentioned that the suspension policy is state contingent, as it relies on the realization of $R$.

18. Notice that as $0 \leq \mu<1$, we have that $\mu \leq \frac{c_{11}^{*}(R)}{c_{21}^{*}(R)}=\frac{1}{\mu}$ and $\mu \leq \frac{c_{22}^{*}(R)}{c_{12}^{*}(R)}=\frac{1}{\mu}$. This means that: $c_{1}^{* 2}(R)=$ $\mu c_{11}^{*}(R)$ and $c_{2}^{* 2}=c_{11}^{*}(R)$. Similarly, $c_{1}^{* 1}(R)=\mu_{21}^{*} c_{11}^{*}(R)$ and $c_{2}^{* 1}(R) \stackrel{c_{12}}{=} c_{11}^{*}(R)$.

19. This means that: $c_{1}^{* 2}(R)=\frac{1+\mu r}{1+\mu} c_{11}^{*}(R) \mu$ and $c_{2}^{* 2}(R)=\frac{1+\mu r}{1+\mu} c_{11}^{*}(R)$ if $r \leq 1 / \mu^{2}$. Otherwise, $c_{1}^{* 2}(R)=c_{11}^{*}(R)$ and $c_{2}^{* 2}(R)=\mu r c_{11}^{*}(R)$. Similarly, as $r>1$ we have that $\mu<\frac{c_{22}}{c_{12}}=\frac{r}{\mu} c_{1}^{* 1}(R)=\mu c_{11}^{*}(R)$ and $c_{11}^{* 1}(R)=$ $r c_{11}^{*}(R)$.

20. In solving this maximization problem, the expected utility and the incentive constraints have been divided by $\rho$.

21. The above solution could be obtained straightforward by assuming that in this case the utilities of both types of agents are equal, and therefore Eq. (62) can be substituted by the following one: $\max \left\{E_{\tilde{R}}\left[\left(t_{1}+\right.\right.\right.$ $\left.\left.\left.\alpha) U^{1}\left(c_{11}(R), c_{21}(R), \rho_{1}\right)+\left(t_{2}-\alpha\right) U^{2}\left(c_{12}(R)\right), c_{22}(R), \rho_{2}\right)\right]\right\}$ that together with constraints (66) and the incentive compatibility conditions (63e) and (63f) represents the first best problem (Case 2), where $t_{1}$ and $t_{2}$ have been substituted by $t_{1}+\alpha$ and $t_{2}-\alpha$, respectively. The solution to this case is given by Eq. (42), modifying $t_{1 m}, t_{2 m}$ and $r$ by the new values $t_{1 m}^{\alpha}, t_{2 m}^{\alpha}$ and $r^{\alpha}$, as given by formulae (33) and (34). In order for this solution to fulfill the incentive compatibility conditions $r^{\alpha}=1$, i.e., $r^{\alpha}=R \frac{\left(k_{2} / k_{1}\right)}{\left(t_{2 m}^{\alpha} / t_{1 m}^{\alpha}\right)}=1$ and from this equation the value of $\alpha(R)$ is derived and coincides with the one given by Eq. (88). Also the consumption levels coincide with the first best case.

\section{References}

ALLEN, F. and GALE, D. [1998]: “Optimal Financial Crises,” Journal of Finance, 53, 1245-1284. 
ALONSO, I. [1996]: “On Avoiding Bank Runs,” Journal of Monetary Economics, 37, 73-87.

BHATTACHARYA, S. and GALE, D. [1987]: "Preference Shocks, Liquidity and Central Bank Policy," in New Approaches to Monetary Economics, W.A. Barnett and K.J. Singletons (Eds.), Cambridge University Press, Cambridge, UK, 69-88.

BRYANT, J. [1980]: "A Model of Reserves, Bank Runs and Deposit Insurance," Journal of Banking and Finance, 4, 335-344.

CHARI, V. and JAGANNATHAN, R. [1988]: "Banking Panics, Information and Rational Expectations Equilibrium," Journal of Finance, 43(3), 749-761.

DIAMOND, D. and DYBVIG, P. [1983]: "Bank Runs, Deposit Insurance and Liquidity," Journal of Political Economy, 91(3), 401-419.

GORTON, G. [1988]: Banking Panics and Business Cycles. Oxford, UK: Oxford University Press.

JACKLIN, C. [1987]: "Demand Deposits, Trading Restrictions and Risk Sharing," in Contractual Arrangements for Intertemporal Trade, E.C. Prescott and N. Wallace (Eds.), University of Minnesota Press, 26-47.

JACKLIN, C. and BHATTACHARYA, S. [1988]: "Distinguishing Panics and Information-Based Bank Runs: Welfare and Policy Implications," Journal of Political Economy, 96, 568-592.

MISHKIN, F. [1995]: The Economics of Money, Banking and Financial Markets. HarperCollins College Publishers.

SAMARTÍN, M. [1997]: "Financial Intermediation and Public Intervention," Ph.D. Thesis, Core, Université Catholique de Louvain.

WALLACE, N. [1988]: "Another Attempt to Explain an Illiqid Banking System: The Diamond Dybvig Model with Sequential Service Taken Seriously," Quaterly Review of the Federal Reserve Bank of Minneapolis, 3-16. 